\title{
ANALISIS RISIKO KELELAHAN OTOT DENGAN METODE CUMMULATIVE TRAUMA DISORDERS RISK INDEX
}

\author{
Ayu Endah Wahyuni ${ }^{1}$, Anita Juraida ${ }^{2}$, Asep Anwar ${ }^{3}$ \\ Fakultas Teknik, Teknik Industri \\ Universitas Widyatama \\ Jl. Cikutra No.204A, Sukapada, Kec. Cibeunying Kidul, Kota Bandung, Jawa Barat 40125 \\ ayu.endah@widyatama.ac.id ${ }^{1}$, anita.juraida@widyatama.ac.id ${ }^{2}$, $\underline{\text { asep.anwar@widyatama.ac.id }}^{3}$
}

\begin{abstract}
Abstrak
PT XYZ membutuhkan tenaga mesin dan kerja fisik operator dalam proses produksi botol plastik. Namun, tenaga manusia memiliki keterbatasan fisik apabila melakukan aktivitas yang berlebihan. Risiko cedera dan kecelakaan kerja yang akan terjadi cukup tinggi apabila dibiarkan. Salah satu, cidera kerja yang dialami oleh operator dalam aktivitas produksi yaitu, gangguan musculoskeletal, cidera ditangan dan sakit pinggang. Hal ini, disebabkan aktivitas kerja yang dilakukan secara berulang-ulang dan mengkibatkan cidera, serta penurunan produktivitas kerja. Oleh karena itu, penelitian ini akan berupaya menemukan solusi permasalahan dengan mengukur level risiko menggunakan pendekatan metode cumulative trauma disorders (CTD) risk index. Hasil penelitian ini menunjukkan bahwa, diperoleh level cidera pada tiga faktor utama dan satu faktor tambahan, meliputi : Frequency Factor (1,98), Posture Factor $(0,9)$ dan Force Factor (3,441), serta Miscellaneous Factor (1). Kemudian, diperoleh CTD Risk Index sebesar 1,996. Hal ini menunjukkan bahwa, CTD Risk Index menghasilkan level risiko kumulatif $>1$. Hal ini dapat mengakibatkan risiko cidera kumulatif pada operator di stasiun kerja, sehingga dapat menimbulkan cidera otot. Dengan demikian, solusi dari permasalahan dari penelitian ini yaitu diperlukan adanya waktu istirahat dan perbaikan layout stasiun kerja, sehingga operator dapat bekerja dengan postur tubuh yang baik dan mencegah terjadinya risiko kerja, kelelahan otot yang mengakibatkan Cumulative Trauma Disorders (CTDs).
\end{abstract}

Kata kunci : cidera, risiko, ctd risk index, operator

\begin{abstract}
$P T X Y Z$ requires mechanical power and physical work of the operator in the process of producing plastic bottles. However, human labor has physical limitations when doing excessive activity. The risk of injury and work accident that will occur is quite high if left unchecked. One of them is work injury experienced by the operator in production activities, namely, musculoskeletal disorders, hand injuries and back pain. This is due to work activities carried out repeatedly and resulting in injuries, as well as decreased work productivity. Therefore, this research will try to find a solution to the problem by measuring the risk level using the cumulative trauma disorders (CTD) risk index approach. The results of this study indicate that injury levels were obtained on three main factors and one additional factor, including: Frequency Factor (1.98), Posture Factor (0.9) and Force Factor (3,441), and Miscellaneous Factor (1). Then, a CTD Risk Index of 1.996 was obtained. This shows that, CTD Risk Index produces a cumulative risk level > 1. This can result in the risk of cumulative injury to the operator at the work station, which can lead to muscle injury. Thus, the solution of the problem from this research is that there is a need for rest and repair work station layout, so that the operator can work with good posture and prevent the risk of work, muscle fatigue resulting in Cumulative Trauma Disorders (CTDs).
\end{abstract}

Keywords : injury, risk, ctd risk index, operator 


\section{Pendahuluan}

PT. XYZ merupakan perusahaan yang memproduksi botol plastik untuk memenuhi kebutuhan masyarakat. Dalam melaksanakan kegiatan tersebut, perusahaan membutuhkan tenaga mesin dan kerja fisik operator. Kerja fisik (phsical work) adalah kerja yang memerlukan energi fisik otot manusia sebagai sumber tenaganya. Kerja fisik seringkali disebut sebagai kerja berat ataupun kerja kasar yang memerlukan usaha fisik manusia yang kuat selama periode kerja berlangsung (Wignjosoebroto, 2008). Manusia mempunyai keterbatasan dalam melakukan kerja fisik. Beban kerja fisik yang berlebihan dapat menimbulkan kelelahan dan cidera kerja, salah satunya adalah gangguan muskuloskeletal (Micheletti dkk, 2019).

Pada saat ini, di PT XYZ banyak ditemukan keluhan operator dalam melakukan pekerjaannya akibat kerja fisik yang berlebihan, misalnya keluhan pegal-pegal di tangan dan sakit pinggang. Keluhan ini terjadi karena setiap harinya operator melakukan pekerjaan secara berulang-ulang, memindahkan barang dengan cara manual, dan melakukan pekerjaan dengan sikap ekstrim yang akan meningkatkan tekanan pada otot. Hal tersebut apabila sering terjadi dalam jangka waktu yang lama akan menimbulkan cidera kerja kumulatif yang berbahaya untuk kesehatan operator dan dapat menimbulkan penurunan produktivitas kerja. Melihat kenyataan tersebut, maka dilakukan penganalisaan mengenai akibat yang terjadi dari permasalahan dan memberikan usulan apa yang dapat dilakukan PT XYZ. Apabila operator mudah mengalami kelelahan maka, hasil pekerjaan yang dilakukan operator tersebut juga akan mengalami penurunan dan tidak sesuai dengan yang diharapkan (Susihono, 2012).

\section{KAJIAN LITERATUR}

\section{II.1 Ergonomi}

Frase "ergonomic" berawal dari dua kata meliputi "ergon" yaitu "kerja" dan "nomos" yaitu "hukum". Istilah ini bermula dari Bahasa Yunani (Bridger, 2003).

Sementara itu, ergonomi diartikan sebagai interaksi antara manusia sebagai operator dengan objek atau alat yang digunakannya dalam aktivitas kerja (Pulat, 1992).

Selain itu, ilmu ergonomi didefiniskan menjadi ilmu yang impelementasinya berusaha untuk menyeimbangkan pekerjaan dan lingkungan antar manusia, agar tercapainya effektivitas dan efisiensi, serta optimalisasi pemanfaatan faktor manusia (Suma'mur, 1989).

\section{II.2 Muskuloskeletal Manusia}

Sistem Muskuloskeletal Manusia terdiri dari tulang dan jaring penghubung serta, aktivitas otot.

Pada tubuh manusia, memiliki struktur kerangka dan berfungsi untuk penyokong dan pelindung, yang terdiri dari 206 tulang (Wickens et al, 2004).

Dengan demikian, system musculoskeletal pada manusia memiliki beberapa fungsi, meliputi :

Tabel 1. Fungsi Muskuloskeletal

\begin{tabular}{ccc}
\hline \hline No. & Skeletal & Muskular \\
\hline \hline 1 & Penyokong & $\begin{array}{c}\text { Aktivitas pergerakan } \\
\text { bagian-bagian tubuh } \\
\text { Postur tubuh yang baik }\end{array}$ \\
2 & $\begin{array}{c}\text { Pelindung (tulang } \\
\text { tengkorak) }\end{array}$ & $\begin{array}{c}\text { Menghasilkan rasa } \\
\text { panas (menjaga }\end{array}$ \\
& Pergerakan/ \\
& aktivitas otot-otot & temperatur tubuh) \\
& yang menempel & \\
& pada tulang & \\
& Homopoiesis & \\
& (tulang yang & \\
& menghasilkan sel & \\
& darah merah) & \\
\hline \hline
\end{tabular}

Ada beberapa faktor yang menyebabkan terjadinya CTDs meliputi : force, postur tubuh, aktivitas/gerakan berulang-ulang dan durasi (Bridger, 2003).

\section{II.3 Musculoskeletal Disorders (MSDs)}

Musculoskeletal Disorders atau MSDs merupakan sejenis gangguan atau cedera yang dapat mempengaruhi pergerakan/aktivitas tubuh, biasayang disebut dengan sistem musculoskeletal, meliputi Otot, tendon, saraf, ligament, pembuluh darah, cakram) (Middlesworth, 2020). dari :

Beberapa jenis gangguan muskuloskeletal terdiri
- Ketegangan otot
- Sindrom Terpal Carpal
- Keseleo Ligamen
- Trigger Finger
- Rotator Cuff Tendonitis
- Cakram yang Pecah
- Epicondylitis
- Sindrom Terowongan Radial 
- Neuritis Digital

- Sindrom DeQuervain

- $\quad$ Sindrom Kembali Mekanis

- Penyakit Disk Degeneratif

Beberapa gangguan tersebut, biasanya diistilahkan sebagai "gangguan muskuloskeletal" karena menggambarkan masalahnya.

Selain itu, istilah lain dari MSD yaitu "cedera gerakan yang berulang" atau "cedera tekanan yang berulang" serta, "cedera yang berlebihan". Hal itu berimplikasi sebagai penyebab tunggal terhadap kerusakan pada sistem muskuloskeletal - pengulangan dan stres. Sehingga, banyak penelitian yang melakukan observasi pada beberapa faktor risiko penyebab MSD (Middlesworth, 2020).

\section{II.4 Cummulative Trauma Disorders (CTD's) Risk Index}

CTD's Risk Index merupakan suatu metode untuk mengetahui tingkat resiko yang dapat terjadi pada suatu aktivitas kerja. Analisis risiko CTD's Risk Index menjumlahkan nilai risiko untuk ketiga faktor penyebab utama menjadi satu skor risiko. Untuk kondisi yang relatif aman, indeks harus lebih kecil daripada satu (Grepo, dkk. 2013).

Model pengukuran CTD's Risk Index bertujuan untuk meramalkan tingkat kejadian cedera (Seth, 1999). Model ini menggunakan data kuantitatif seperti frekuensi gerakan tangan dalam memperoleh skor faktor frekuensi, sehingga mencerminkan ketegangan yang berada pada otot dan tendon pergelangan tangan. Pada postur ekstremitas dimasukkan ke dalam skor faktor postur dan berbagai stresor pekerjaan kecil dimasukkan sebagai skor faktor seluler.

\section{Analisis dan Perancangan}

\section{III.1 Pengumpulan Data}

Pengumpulan data ini dilakukan pada saat shift sore. Pengumpulan data terdiri dari 3 faktor utama dan 1 faktor tambahan, yaitu frecuency factor, posture factor, force factor, dan miscellaneous factor.

\section{Frecuency Factor}

Data untuk frecuency factor yaitu job title, job description, part/day, rest time/lunch didapat dari hasil wawancara, sedangkan cycle time dan handmotions/cycle didapat dari pengamatan langsung terhadap operator yang sedang bekerja di stasiun kerja peniupan preform. Data frecuency factor dapat dilihat pada Tabel 2.

Tabel 2. Data Frecuency Factor

\begin{tabular}{cc}
\hline Data Frecuency Factor & Keterangan \\
\hline Cycle Time & 6 detik \\
Lunch & 0 detik \\
Break & 0 detik \\
Part/60 minutes & 1800 buah \\
Handmotions/Cycle & 11 kali \\
\hline \hline
\end{tabular}

\section{Posture Factor}

Data untuk posture factor didapat dari foto postur tubuh operator yang sedang bekerja dan diberi sudut untuk dilakukan pengolahan data.

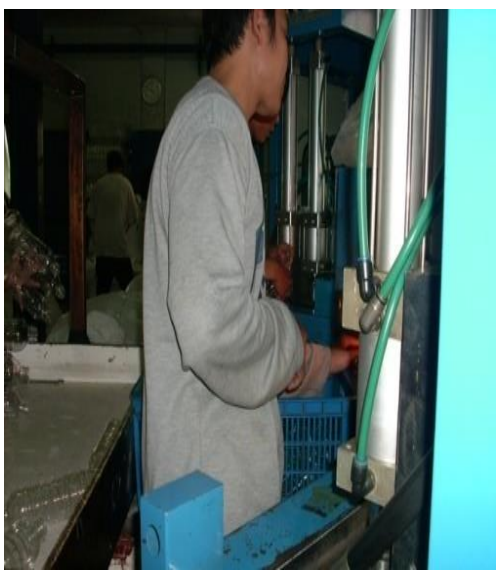

Gambar. 1 Foto Operator

Posisi operator berdiri saat bekerja dengan ditopang oleh kedua kaki. Operator menekukkan tangan saat memegang benda dengan posisi ibu jari dan telunjuk menjepit saat memegang benda. Operator menjangkau dan memindahkan benda kerja dari kiri ke kanan atau sebaliknya, dengan lengan bawah operator bergerak dari kanan ke kiri atau sebaliknya saat bekerja. Sudut posisi siku saat bekerja $19,88^{\circ}$. Sudut dari posisi bahu tampak depan saat bekerja $33,72^{\circ}$. Sudut dari posisi bahu tampak samping bekerja $29,12^{\circ}$. Serta posisi leher saat bekerja menunduk sebesar $56,5^{\circ}$.

\section{Force Factor}

Beban yang diangkat pada saat bekerja adalah 0,016 $\mathrm{kg}$ dan beban maksimal yang diangkat pada saat melakukan pekerjaan yang sama adalah $0,031 \mathrm{~kg}$.

\section{Miscellaneous Factor}


Data yang dibutuhkan untuk miscellaneous factor adalah sharp edge, glove, vibration, type of action, dan temperature. Keterangan lebih jelas dapat dilihat pada Tabel 3.

Tabel 3. Data Miscellaneous Factor

\begin{tabular}{cc}
\hline \hline Miscellaneous Factor & Keterangan \\
\hline \hline Sharp Edge & Operator tidak selalu \\
blove & lancip \\
& Operator tidak \\
Vibration & menggunakan sarung \\
& tangan pada saat bekerja \\
Type of Action & Operator dipengaruhi \\
& getaran pada saat bekerja \\
& Operator bekerja \\
Temperature & secara tidak statis dan tidak \\
& dinamis \\
& Operator bekerja pada \\
& temperatur panas \\
\hline \hline
\end{tabular}

\section{III.2 Pengolahan Data}

Pengolahan data dilakukan dengan menggunakan worksheet CTDs Risk Index. Tiga faktor utama yaitu frequency, posture factor, force factor dan 1 faktor tambahan yaitu miscellaneous factor, dilakukan perhitungan untuk menentukan level risiko cidera kerja.

\section{Frequency Factor}

Sebelum mendapatkan nilai Frequency Factor, hal pertama yang dihitung adalah cycle/60 minutes, didapatkan dengan rumus:

$$
\text { Cycle } / 60 \text { minutes }=\frac{(60-\text { lunch-break }) \times 60}{\text { cyle time }}
$$

Nilai Cycle/60 minutes dibandingkan dengan part/60 minutes, nilai yang paling besar dikali dengan handmotions/cycle untuk mendapatkan nilai handmotions $/ 60$ minutes. Lalu nilai handmotions $/ 60$

Tabel 4. Rekapitulasi Perhitungan CTDs Risk Index

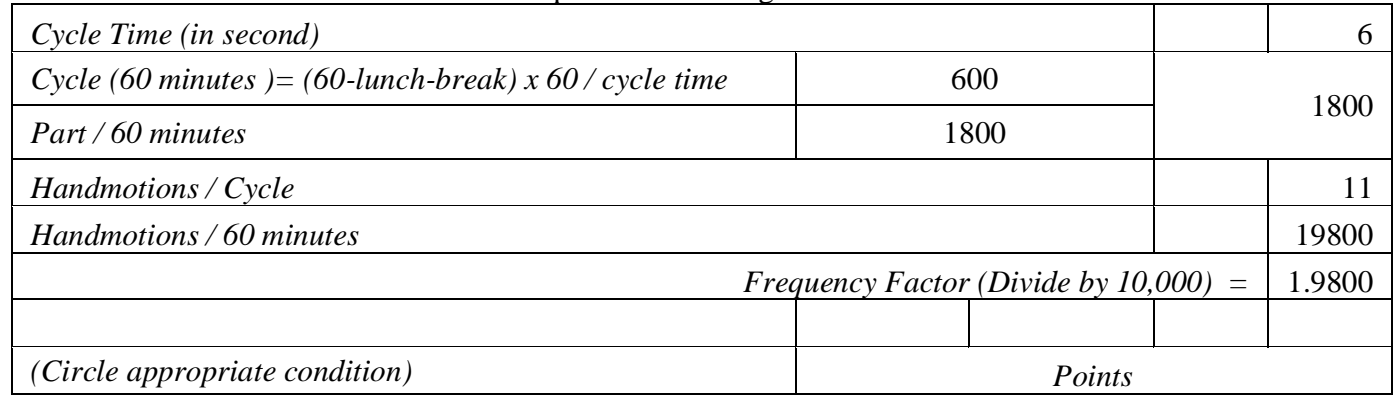

Ayu Endah Wahyuni, Anita Juraida, Asep Anwar 


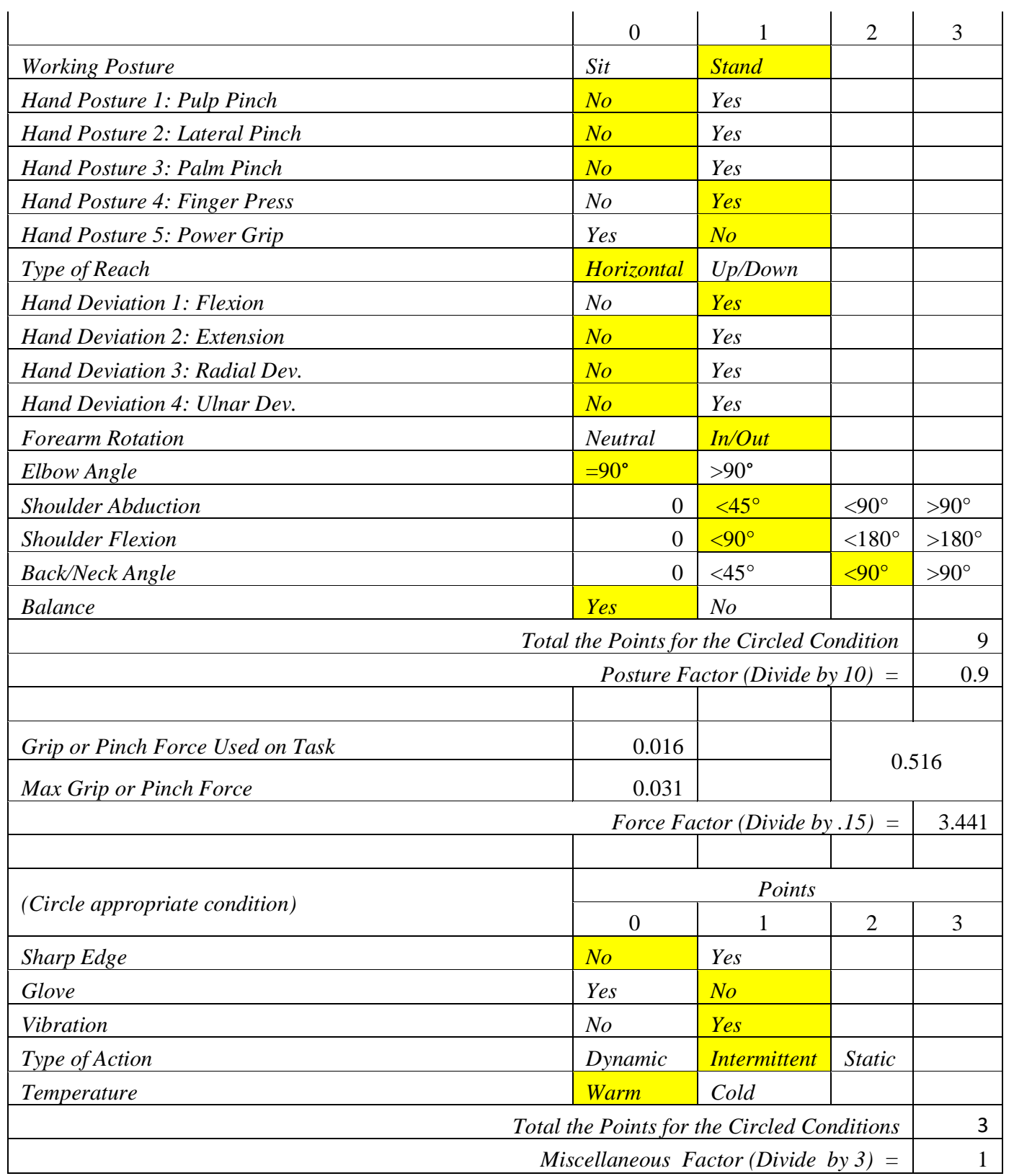

\section{ANALISIS}

Setelah mendapatkan level cidera kerja pada tiap faktor, maka dicari CTD Risk Index dengan cara:

CTD Risk Index $=(0,3 \times$ (Frequency Factor + Posture Factor + Force Factor $))+(0,1 \mathrm{x}$ Miscellaneous Factor $)=(0,3 \times(1,98+0,9+3,441))+$ $(0,1 \times 1)=1,996$
Hasil pengolahan data menunjukkan hasil level risiko cidera kumulatif $>1$, yaitu sebesar 1,996 . Hasil tersebut menunjukkan adanya risiko cidera kumulatif pada stasiun kerja di PT. XYZ. Dalam jangka waktu yang lama operator di stasiun kerja tersebut dapat mengalami cidera kerja akibat Cumulative Trauma Disorders (CTDs). Gangguan ini akan menyebabkan

Ayu Endah Wahyuni, Anita Juraida, Asep Anwar 
rasa tidak nyaman, cacat, atau nyeri di sendi, otot, tendon, dan jaringan lunak lainnya (Tuncer dkk, 2015).

Hasil level risiko cidera kumulatif dipengaruhi oleh hasil frecuency factor, posture factor, force factor, dan miscellaneous factor. Dimana terdapat dua faktor yang $>1$, yaitu level risiko cidera frecuency sebesar 1,98 dan force factor sebesar 3,441. Hal tersebut dapat disimpulkan terjadi pengulangan (repetitive) pekerjaan yang cukup tinggi dengan membawa beban. Gerakan repetitive akan mengakibatkan penurunan kekuatan maksimal otot sehingga terjadi kelelahan otot (Wan dkk, 2017).

Level risiko cidera posture factor < 1, yaitu sebesar 0,9 dan level risiko cidera miscellaneous factor $=1$. Nilai tersebut tidak menunjukkan adanya risiko cidera kerja, namun level tersebut mendekati 1 , sehingga dapat disimpulkan terdapat kondisi posisi operator yang buruk dan dapat menimbulkan cidera kerja. Kondisi yang dapat menimbulkan cidera kerja salah satunya adalah operator bekerja dengan selama 8 jam dengan posisi berdiri. Berdiri dengan posisi yang lama akan menyebabkan ketidaknyamanan bagianbagian tubuh, khususnya punggung bawah, paha dan kaki (Azizzati dkk, 2013).

\section{KESIMPULAN DAN SARAN}

Hasil penelitian ini memperoleh CTDs Risk Index, melalui tiga faktor utama dan satu faktor tambahan yaitu, frequency factor $(1,98)$, posture factor $(0,9)$ dan force factor $(3,441)$, serta miscellaneous factor (1). Sehingga, diperoleh level risiko cidera kumulatif $>1$, yaitu sebesar 1,996. Angka ini, menunjukkan aktivitas yang adanya risiko cidera kumulatif pada stasiun kerja, yang mengakibatkan cidera kerja, cacat, nyeri sendi dan gangguan jaringan lunak pada anggota tubuh. Adanya akyivitas kerja yang berulang (repetitive) cukup tinggi akan menyebabkan kelelahan. Oleh karena itu, Usulan pemecahan masalah dari penelitian ini adalah adanya waktu istirahat serta perbaikan layout stasiun kerja agar operator dapat bekerja dengan postur tubuh yang baik, mengingat kelelahan otot dalam jangka waktu yang lama akan mengakibatkan Cumulative Trauma Disorders (CTDs).

\section{UCAPAN TERIMA KASIH}

Penulis mengucapkan terima kasih kepada Kementerian Riset dan Teknologi / Badan Riset dan Inovasi Nasional atas Hibah Penelitian Dosen Pemula
(PDP) Tahun 2020 dengan Nomor Kontrak Nomor: 002/SP4/LP2M-UTAMA/VI/2020.

\section{REFERENSI}

Azizzati, S., N., Wahab, N., Ahmad, I.,N., Bay, H., and Ma'arof, M., I.,N. 2013. A Review of Studies Concerning Prolonged Standing Working Posture. Advanced Engineering Forum vol.10 pp 131-136.

Bridger, R. S. 2003. Introduction to Ergonomics: Second Edition. New York: Taylor and Francis.

Grepo, L., Yabis, D.,J., and Po, R., A. 2013. An Evaluation Of Manual Meterial Handling Tasks In A Manufacturing Company. Proceeding of 2013 International Conference On Technology Innovation and Industrial Management. Phuket: University of the Philippines.

Micheletti, J., K., Blafoss, R., Sundstrup, E., Bay, H., Pastre, C., M., and Andersen L., L. 2019. Association Between Lifestyle and Musculoskeletal Pain: Cross- Sectional Study Among 10,000 Adults From The General Working Population. BMC Musculoskeletal Disorders.

Pulat, B. Mustafa. 1992. Fundamentals of Industrial Ergonomics. New Jersey: Prentice-Hall, Inc.

Tuncer, O., B., Gen, H., Nacir, B., and Erdem, H. R. 2015. Determining Risk Factors in Cumulative Trauma Disorders of Computer Users and Effects of Risk Factors on Disability. Turk J Phys Med Rehab 2015;6, pp 298-306.

Seth, V., Weston, R.L., and Freivalds, A., 1999. Development of cumulative trauma disorder risk assessment model for the upper extremities. International Journal of Industrial Ergonomics, 23, 281-291.

Susihono, W., Prasetyo, W. 2012. Perbaikan Postur Kerja Untuk Mengurangi Keluhan Muskuloskeletal Dengan Pendekatan Metode Owas. Spektrum Industri, 10(1).

Wan, J., Qin, Z., Wang, P., Sun, Y. and Liu, X., 2017. Muscle fatigue: general understanding and treatment. Experimental \& Molecular Medicine, 49(10), pp.e384-e384.

Wickens, Christopher D. et al. 2004. An Introduction to Human Factors Engineering: Second Edition. New Jersey: Pearson Prentice Hall.

Wignjosoebroto, Sritomo, 2008, Ergonomi Studi Gerak dan Waktu, Guna Widya, Surabaya.

Ayu Endah Wahyuni, Anita Juraida, Asep Anwar 